\title{
ASPECTOS TERRITORIALES DE LA ACTIVIDAD TURÍSTICA EN CUBA
}

\author{
POR \\ EROS SALINAS CHÁVEZ \\ $\mathrm{Y}$ \\ RAMÓN ESTEVEZ PAZÓ
}

Origen y evolución del turismo en Cuba

El surgimiento del turismo en Cuba y su desarrollo ha estado en correspondencia estrecha con la historia económica y político-social del país. En el siglo xIx y en la primera mitad del siglo xx, el desarrollo turístico en Cuba estuvo caracterizado, en términos generales, por la inexistencia de una política definida para aumentar o sostener los avances alcanzados en ciertos períodos.

Entre las primeras referencias de archivo de llegadas de visitantes extranjeros se encuentran, a finales del siglo pasado, los registros del antiguo Hotel Trocha, ubicado en el actual barrio del Vedado, en La Habana, donde aparece la descripción de un gran número de ciudadanos norteamericanos que venían a Cuba por diferentes motivos, paseos y negocios.

El primer intento de organizar la actividad turística con el propósito de su fortalecimiento, se realizó el 8 de agosto de 1919, con la creación oficial de la llamada Comisión Nacional para el Fomento de Turismo; por lo cual, se puede afirmar que el surgimiento del turismo como industria se produce en esta fecha. A partir de entonces, se 
comenzaron a construir una serie de obras con fines turísticos, proceso que se apoyó en el gran auge económico nacional, resultado del alza desmedida de los precios del azúcar, en el mercado internacional, al concluir la Primera Guerra Mundial.

Estos factores motivaron un crecimiento continuo en la entrada de visitantes extranjeros con fines turísticos, el que se mantuvo, de acuerdo con informaciones estadísticas, hasta 1928. A partir de ese año, se inició un período de crisis en la estructura económica del país, que influyó en la industria turística y cuyo decrecimiento fue máximo en 1934. En el período de 1935-1941, se manifiesta un crecimiento en el número de visitantes, reflejado en las siguientes cifras:

CUADRo I

TURISMO EN CUBA (1934-1941)

Promedio anual de visitantes

Promedio de gasto por visitante $\$$

Promedio de permanencia por visitante ................................ 8 días

Ingreso por concepto de turismo $\$$.................................. 98.702.600.00

FueNTE: Estadísticas Bancarias del Banco Nacional de Cuba. 1995.

La Segunda Guerra Mundial provocó la caída vertical del turismo en el mundo, pero con su fin, en 1945, volvió a establecerse un alza en los viajes turísticos y en general para el desarrollo de la principal rama económica de Cuba: el azúcar. Este hecho, unido a las facilidades brindadas para viajar al extranjero, trajo como consecuencia la salida de los grupos de cubanos de más altos ingresos, que gastaron más dinero en el exterior que el dejado por los turistas extranjeros en el país, lo cual provocó, como saldo, un déficit que se mantuvo hasta mediados de la década de los cincuenta (véase cuadro II).

Desde el punto de vista económico, se ha comprobado que el turismo de esta época siguió en importancia a la llamada «segunda industrial nacional» (el tabaco), de acuerdo con los ingresos percibidos; aunque ya en 1957 llegó a ocupar el segundo lugar, después del azú- 
Cuadro II

EVOLUCIÓN DE LOS GASTOS DE TURISMO (1946-1958)

(EN MILLONES DE PESOS)

\begin{tabular}{|c|c|c|c|}
\hline Año & $\begin{array}{c}\text { Egresos } \\
\text { por turismo }\end{array}$ & $\begin{array}{c}\text { Ingresos } \\
\text { por extranjero }\end{array}$ & $\begin{array}{c}\text { Turismo cubano } \\
\text { al exterior } \\
\text { Saldo }\end{array}$ \\
\hline $1946 \ldots \ldots \ldots \ldots \ldots \ldots \ldots \ldots \ldots \ldots \ldots \ldots \ldots \ldots \ldots$ & 10,4 & 14,8 & $-4,4$ \\
\hline 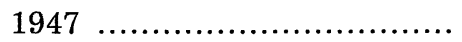 & 14,8 & 23,4 & $-8,6$ \\
\hline 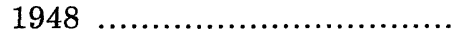 & 14,3 & 97,0 & $-12,7$ \\
\hline 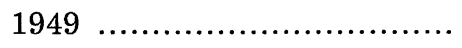 & 15,5 & 27,3 & $-11,8$ \\
\hline (n................ & 17,1 & 31,6 & $-14,5$ \\
\hline 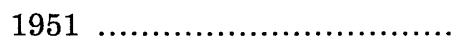 & 19,2 & 29,4 & $-10,2$ \\
\hline $1952 \ldots \ldots \ldots \ldots$ & 19,2 & 32,2 & $-13,0$ \\
\hline 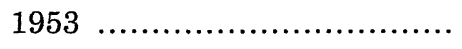 & 19,6 & 30,8 & $-11,2$ \\
\hline 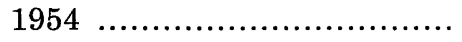 & 24,0 & 31,6 & $-7,6$ \\
\hline 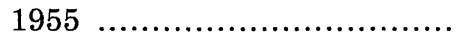 & 27,8 & 30,8 & $-3,0$ \\
\hline 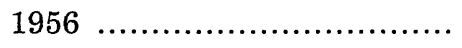 & 38,1 & 33,8 & $+4,3$ \\
\hline 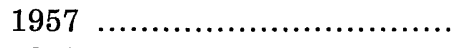 & 62,1 & 38,5 & $+23,6$ \\
\hline 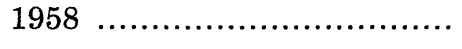 & 56,9 & 37,5 & $+19,4$ \\
\hline
\end{tabular}

Fuente: Banco Nacional de Cuba: Estadísticas Bancarias, BNC, La Habana, 1959, e Información y Estadistica, Dirección de Inmigración y Extranjería, La Habana, 1960.

car, en relación con la totalidad de las exportaciones. Uno de los factores influyentes en el desarrollo del turismo, fue el incremento de las inversiones hoteleras, en especial el auge producido desde 1952 hasta 1958. En este intervalo de tiempo, arrojaron un aumento de capacidad de alojamiento de 5.464 personas, lo cual, unido al incremento de las existentes por ampliaciones y al aumento del alojamiento no hotelero (casas y apartamentos), hicieron que la capacidad se incrementara a no menos de 6.642 personas. Este saldo cuantitativo permitía superar uno de los factores que más frenaba el desarrollo turístico del país (véanse cuadros III, IV y V).

En 1957 se alcanzó la cifra más alta de turismo extranjero: 272.265 visitantes, de los cuales el $85 \%$ eran norteamericanos atraídos en su gran mayoría, por la publicidad denigrante que ofrecía La Habana, como centro de juegos y prostitución del Caribe. De esta forma, Cuba ocupó el primer lugar como receptor del área caribeña, lo

$$
-329-
$$


cual contrastaba con la insignificante cantidad de turistas nacionales, aplastado por una realidad de pobreza caractericada por: desempleo, descriminación racial, insalubridad y subdesarrollo en general, que padecía la mayor parte de la población.

Cuadro III

CAPACIDAD HOTELERA DE CUBA A FINES DE 1951

\begin{tabular}{|c|c|c|}
\hline Provincia & $\begin{array}{c}\text { Número de } \\
\text { habitaciones }\end{array}$ & $\begin{array}{c}\text { Capacidad de } \\
\text { alojamiento }\end{array}$ \\
\hline Pinar del Río ........... & 172 & 352 \\
\hline 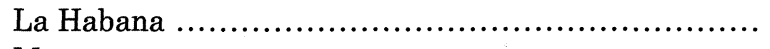 & 4.118 & 7.636 \\
\hline 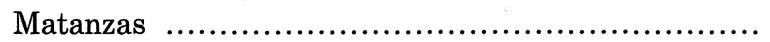 & 1.000 & 2.153 \\
\hline Las Villas ............. & 462 & 641 \\
\hline 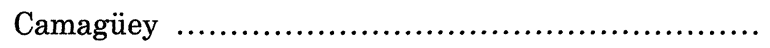 & 418 & 650 \\
\hline 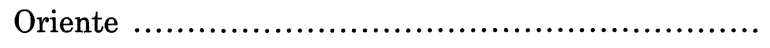 & 382 & 635 \\
\hline TOTAL & 6.552 & 12.067 \\
\hline
\end{tabular}

FuENTE: Banco Nacional de Cuba: Estadisticas bancarias, BNC, La Habana, 1955.

CUADRO IV

VALOR DE LAS INVERSIONES Y CAPACIDAD DE NUEVOS HOTELES Y MOTELES (1952-1958)

\begin{tabular}{|c|c|c|c|}
\hline Provincia & $\begin{array}{c}\text { Valor de la } \\
\text { inversión } \\
\text { (miles USD\$) }\end{array}$ & $\begin{array}{l}\text { Número de } \\
\text { habitaciones }\end{array}$ & $\begin{array}{l}\text { Capacidad de } \\
\text { alojamiento }\end{array}$ \\
\hline Pinar del Río . & - & - & - \\
\hline La Habana .......................... & $55.592,6$ & 2.384 & 4.532 \\
\hline 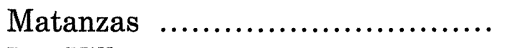 & $1.050,0$ & 54 & 108 \\
\hline Las Villas ........................... & $1.626,8$ & 251 & 506 \\
\hline Camagüey .......................... & 650,0 & 93 & 170 \\
\hline 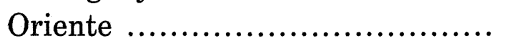 & 350,0 & 85 & 148 \\
\hline TotaL ............................ & $59.269,4$ & 2.867 & 5.464 \\
\hline
\end{tabular}

Fuente: Banco Nacional de Cuba: Estadisticas Bancarias, BNC, La Habana, 1959.

$$
-330-
$$


ASPECTOS TERRITORIALES DE LA ACTIVIDAD TURÍSTICA EN CUBA

CuAdro V

AMPLIACIONES EFECTUADAS EN HOTELES Y MOTELES (1952-1958)

\begin{tabular}{|c|c|c|c|}
\hline Provincia & $\begin{array}{c}\text { Valor de la } \\
\text { inversión } \\
(\text { miles USD\$) }\end{array}$ & $\begin{array}{c}\text { Número de } \\
\text { habitaciones }\end{array}$ & $\begin{array}{l}\text { Capacidad de } \\
\text { alojamiento }\end{array}$ \\
\hline Pinar del Río .......................... & - & - & - \\
\hline La Habana ............................ & $2.752,0$ & 104 & 208 \\
\hline 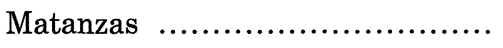 & 700,0 & 128 & 264 \\
\hline Las Villas ............................... & - & - & - \\
\hline 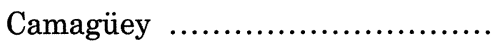 & - & - & - \\
\hline 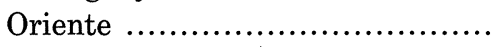 & 30,0 & 53 & 106 \\
\hline ............... & $3.482,0$ & 285 & 578 \\
\hline
\end{tabular}

Fuente: Banco Nacional de Cuba: Estadisticas Bancarias, BNC, La Habana, 1959.

Con los cambios promovidos por la Revolución cubana, a partir de 1959, se centró la atención en el incremento y desarrollo de un turismo nacional de carácter popular, que permitiera el acceso y disfrute masivo por parte de la población a los centros turísticos y recreativos. En marzo de 1959, la Ley 270 establece el libre acceso sin distinción de personas a todas las playas y áreas litorales. En noviembre de ese mismo año, se dispuso la creación con carácter autónomo y personalidad jurídica propia del Instituto Nacional de la Industria Turística (INIT), cuyos objetivos básicos de trabajo eran: 1 . Programación de la política de fomento turístico. 2. Ejecución de los planes de desarrollo turístico. 3. Conservación y fomento de las riquezas naturales cubanas. 4. Protección del patrimonio histórico y cultural de la nación que sea relevante a los fines del turismo. 5. Promover la supresión progresiva de todas las causas del subdesarrollo turístico cubano.

En la década de 1960, la recepción de turistas extranjeros mantuvo una tendencia decreciente, expresión de la dependencia absoluta del mercado de EE. UU. En 1962, sólo visitaron Cuba 361 turistas. Resultado de la ruptura de las relaciones diplomáticas entre los dos países, la declaración de bloqueo económico y comercial y la prohibición de viajar a Cuba a los ciudadanos norteamericanos. Devino en- 
tonces un período casi nulo de concurrencia de turismo internacional, en el que, los pocos visitantes que llegaban provenían de los otrora países socialistas de Europa y un número insignificante de viajeros de otros países por razones de solidaridad.

A partir de 1970, comienzan a llegar turistas organizados en grupos desde Canadá y de algunos países de América Latina, al tiempo que aumentan los grupos procedentes de Europa oriental y occidental. Con la irrupción del mercado canadiense, el turismo internacional se somete a un intenso trabajo de recuperación. En 1973, se define la política general de desarrollo del turismo por parte del Consejo de Ministros, fundamentada en la continuación del desarrollo de esta rama, en todas sus modalidades, y en la creación de un apoyo financiero mediante los ingresos derivados por dicho concepto. Con este propósito, se comienza el aprovechamiento de las instalaciones turísticas que durante los meses de octubre a abril, permanecían en parte ociosas, a la vez que se inician numerosas inversiones de alojamiento y servicios. En noviembre de 1976, como resultado de la reestructuración de las instituciones administrativas del país, toda la actividad turística, se centra en un organismo especializado, y de esta forma se crea el Instituto Nacional de Turismo (INTUR) con funciones de planificación y ejecución de la política de desarrollo turístico nacional y extranjero. En lo que respecta a su distribución territorial y administración, la rama turística ha experimentado los cambios más dinámicos de la organización económica y empresarial ocurridos en Cuba. Por un lado, el desafío de la competencia de un turismo en la región del Caribe y de otros países del Tercer Mundo, que promueven similares atractivos naturales con una experiencia ininterrumpida y superior a la cubana, y por otro lado, la coincidencia en la búsqueda de soluciones al más corto plazo posible a los problemas económicos de cada uno. El funcionamiento de una administración estatal centralizada no podía prever siempre soluciones ágiles, a veces locales, a los diferentes problemas que se originan como consecuencia del desarrollo turístico, y los cuales requerían en ocasiones la participación de empresarios extranjeros experimentados, con interés de trabajar en Cuba. En febrero de 1982, se promulga el Decreto-ley 50, que regula la asociación económica entre entidades cubanas y extranjeras, la cual, de acuerdo con medios especializados, se considera como un 
instrumento para expandir, de forma más dinámica, las exportaciones y el turismo.

Con la promulgación de esta ley se comenzó a estimular la asociación de empresas mixtas y sociedades cubanas con capital extranjero, la explotación conjunta de instalaciones, el incremento de representaciones de firmas comerciales y de turismo interesadas en trabajảr en típicos de menos experiencia en Cuba vinculados con la economía de mercado, investigaciones de mercados, gerencia y administración, financiamiento e inversiones. De esta forma, se desagregó el papel del INTUR como única organización administradora de turismo y ya en 1987, surge la Corporación Cubanacán de Comercio Exterior y Turismo, y en 1988 el Grupo Gaviota, S. A.

Por su estructura y financiamiento, estas dos corporaciones trabajan fundamentalmente bajo el esquema de asociación mixta con capital extranjero multinacional. Son reconocidas las inversiones realizadas con el objetivo de poner en explotación nuevos polos turísticos como: el norte de la provincia de Holguín, Santiago de Cuba (Baconao y playa Sevilla) y el subarchipiélago de Sabana y Camagüey y amplias zonas de Varadero. Hoteles para hombres de negocios y servicios de atención médica en Ciudad de La Habana, además de otras modalidades del turismo de salud en Topes de Collantes y diferentes balnearios de aguas minero-medicinales de Pinar del Río y Matanzas, por sólo mencionar algunos.

A partir de la VI Conferencia Cumbre de los Países No Alineados celebrada en La Habana en 1979, se comenzó a promover el turismo de eventos científicos, sociales y congresos, no sólo en esta instalación, sino en diversas instituciones científicas, investigativas y docentes. En la actualidad, existen cerca de unas 90 firmas comerciales extranjeras y nacionales relacionadas directa o indirectamente con el turismo, que trabajan en su desarrollo, explotación o comercialización. Un nuevo Decreto-ley aprobado en 1995 por el Parlamento Nacional aumenta las facilidades para la inversión extranjera en diferentes modalidades y en distintas ramas de la economía, entre ellas el turismo. Además, se han firmado hasta fines de 1995, diez acuerdos para la promoción y protección recíproca de inversiones entre Cuba y otros países. 
En cuanto al turismo nacional, como se ha explicado, antes del triunfo de la Revolución en 1959, existía una fuerte tendencia a vacacionar en el extranjero por la burguesía criolla, en lo fundamental a Estados Unidos de América. Desde 1959 se transforma también la composición social del turismo cubano al exterior. Los años 1963-1964 marcaron el comienzo de los viajes de cubanos al exterior, principalmente a la antigua URSS y otros países de Europa Oriental.

Entre los tipos de turismo nacional que han alcanzado grandes ritmos de crecimiento, por su aceptación por la población, se encuentra el campismo. Sus inicios datan de 1975, aunque antes de esta fecha, puede afirmarse que ya existía cierta práctica de esta actividad, sobre todo entre la juventud. En sus inicios, el desarrollo del campismo tuvo distintas dificultades, entre las que sobresalían la ausencia de tradición y hábitos de consumo por parte de la población, insuficiencias en la base material de las instalaciones, pobreza en los servicios gastronómicos y una baja oferta de servicios recreativo-deportivos. En la actualidad, esta situación ha variado por completo, lo cual se evidencia por un gran número de participantes y los altos ritmos de crecimiento de las construcciones destinadas a esta modalidad. El campismo ha sido una vía bien acogida para la solución de los problemas que trae consigo el descanso masivo de la población.

Todas las formas enumeradas de turismo nacional, en uno u otro grado, tienen una marcada estacionalidad en el período de verano debido a los siguientes factores: hábitos de la mayor parte de la población a descansar en los meses de julio y agosto; vacaciones escolares en este mismo período, lo cual permite a la familia vacacionar en su conjunto; unido a que durante estos meses es muy favorable el estado del tiempo para el disfrute del mar.

La última reestructuración en la esfera del turismo ocurrió hace apenas dos años con la creación del Ministerio del Turismo que tiene como objetivo principal establecer las políticas de desarrollo turístico nacional pero no administrar ninguna instalación, aparecieron las cadenas hoteleras: Gran Caribe (hoteles de 5 y 4 estrellas), Horizontes (3 y 2 estrellas), Islazul para atender al turismo nacional y el Grupo 
de Recreación y Turismo Rumbos, al mismo tiempo se fortaleció las labores de Cubamar para el desarrollo del turismo juvenil y de naturaleza. Todas estas empresas están facultadas por el Estado cubano para firmar asociaciones con entidades extranjeras atendiendo a la legislación vigente en Cuba.

\section{Caracteristicas naturales de interés turisticos}

El carácter insular de Cuba y su relieve litoral de $6.073 \mathrm{~km}$ de longitud de costas, permiten la existencia de numerosas y bellas playas, consideradas entre las mejores del Caribe debido a su extensión, calidad de sus arenas (blancas y finas) y transparencia de sus aguas. La longitud de playas de interés turístico es de $345 \mathrm{~km}$; de ellas 225 $\mathrm{km}$ en la costa norte y $120 \mathrm{~km}$ en la costa sur. Debe destacarse la importancia que tiene la combinación funcional y estética de las playas cubanas con las costas abrasivas (acantilados) y biogénicas (manglares). Esta variedad de paisajes litorales aumenta la diversidad paisajística del territorio, y permite establecer amplios programas de actividades recreativas.

En Cuba el turismo de ciudad y el de playa ocupan el primero y el segundo lugar respectivamente, por el número de instalaciones que poseen y la cantidad de turistas recibidos. A estos tipos de turismo le siguen con menor importancia: el turismo de salud, el de congresos y convenciones y el ecoturismo, también conocido como turismo ecológico. Este último tiene una significativa importancia para Cuba, que puede llegar a convertirse en uno de los principales mercados receptores de ecoturistas en el Caribe insular y América Central. En las ciudades y en las playas cubanas la infraestructura turística tiene una tendencia a la concentración territorial, con el propósito de organizar importantes polos de atracción y desarrollo, sobre la base de la calidad y cantidad de los recursos turísticos, en lo fundamental naturales.

Otros recursos además de las playas y de las ciudades, en la formación de los polos turísticos son los ríos, lagunas y embalses. Cuba dispone de una densa red fluvial. Sin embargo, sus ríos por regla general, sus cortos y de poco caudal a consecuencia de la forma alarga-

$$
-335-
$$


da y estrecha del territorio y de su relieve. Entre el $40-50 \%$ de las instalaciones de campismo se localizan en las orillas de los ríos, y un $6 \%$ en los alrededores de los embalses. Cuba cuenta con un apreciable potencial de fuentes de aguas y fangos minero-medicinales, cerca de cien de alta calidad, a pesar de las riquezas existentes, esta actividad está aún poco desarrollada.

Desde el punto de vista turístico, la flora cubana es de gran interés por tres características principales: riqueza extraordinaria de especies, endemismo considerable y gran diversidad de comunidades vegetales. La fauna cubana tiene entre sus características más destacadas la riqueza de especies y subespecies con un predominio de los grupos inferiores (moluscos, insectos y arácnidos), relativa pobreza de la fauna vertebrada con predominio de las aves y ausencia total de mamíferos de gran talla.

En resumen, se puede afirmar que son el clima, la estructura geólogo-geomorfológica y la insularidad, los tres factores físico-geográficos más importantes que definen y caracterizan el potencial turísticorecreativo de los recursos naturales de Cuba, en particular de sus paisajes. La combinación e interrelación de estos tres elementos, ofrece a los turistas una visión sobresaliente y concreta de la imagen de la naturaleza cubana.

Los recursos turísticos con que cuenta el país son suficientes para ofrecer al visitante un producto turístico diversificado e integral que, por sus características, tenga una satisfactoria aceptación en el mercado internacional y sea competitivo con otros territorios del área caribeña. La diversificación de estos recursos se observa en lo referente a sus componentes naturales, histórico-culturales y socioeconómicos que forman parte de la oferta turística, además de las posibilidades de uso que brinda la infraestructura existente. Unidos a estos diferentes aspectos, y como una importante adición a ellos, está la seguridad y hospitalidad brindada por el pueblo cubano. Semejante al axioma de que no debe basarse el desarrollo turístico de un país en un solo mercado por las altas y bajas que bruscamente pudiera tener el mismo, se considera que tampoco se debe basar la explotación turística en un solo recurso, por ejemplo, las playas, por muy buenas que éstas sean.

$$
-336-
$$




\section{Regiones turísticas de Cuba}

Los primeros pasos en este tipo de trabajo fueron dados en Cuba en 1978, fecha en que se elaboró entre los investigadores del INTUR y la Facultad de Geografía de la Universidad de La Habana, el Esquema Preliminar de Regionalización Turistica de Cuba. Como documento primario, este trabajo se fundamentó en la estructura de veinte regiones turísticas con una comunidad de diversos recursos, y sus límites obedecieron en lo fundamental a criterios puramente geográficos (límites de las regiones naturales y zonas físico-geográficas), además de tomarse en cuenta, decisiones de índole política y administrativa.

En 1979, estas mismas Instituciones elaboraron un nuevo documento titulado Propuesta de Regionalización Turística de Cuba, el cual recogía la experiencia del anterior trabajo y completaba algunos aspectos, que no estaban bien definidos en el primero. Los objetivos previstos en este estudio fueron: Definir la localización de los recursos turísticos, brindar una breve descripción de los mismos y delimitar las regiones turísticas, así como servir de base para investigaciones posteriores, que se acometerían sobre la factibilidad de determinados programas de desarrollo turístico nacionales, provinciales y locales. Con el propósito de poder definir las regiones turísticas, se clasificaron los recursos en dos grupos: recursos turísticos básicos y complementarios.

Como recursos turíscos básicos se consideraron aquellos que por sus características podían fundamentar la localización de la infraestructura de alojamiento, por ejemplo: playas, presas, ríos, lagunas, zonas de paisajes, fuentes de aguas minero-medicinales y ciudades de interés turístico. En contrapartida, se consideraron como recursos complementarios: zonas de caza, pesca, cavernas, saltos de agua, museos, monumentos nacionales y zonas de paisajes submarinos.

De esta forma se definió la región turística como aquella parte del territorio integrada por elementos de interés contiguos, donde al menos uno de ellos tenía un carácter básico. Los límites de dichas regiones se establecieron sobre la base de la actual división político-administrativa, las regiones naturales y zonas físico-geográficas de Cuba, así como los vínculos tradicionales de uso entre recursos. En 
este trabajo se definieron 21 regiones. En 1985 se realizó una nueva regionalización turística de Cuba, partiendo no sólo de los recursos existentes y su agrupamiento, sino también de los niveles de asimilación del territorio, determinados por la concentración territorial de las instalaciones, el llamado Índice de Nivel de Asimilación Turística.

$$
\mathrm{Ar}=\frac{\mathrm{Dp}}{\mathrm{k} \times \mathrm{Da} \times \mathrm{H}} 10
$$

Donde: Ar: nivel de asimilación turística del territorio; Dp: densidad de plazas de alojamiento por $\mathrm{km}^{2}$; $\mathrm{k}$ : coeficiente que caracteriza las condiciones que presentan un territorio para el desarrollo de la actividad de turismo, calculado según la tipología de las áreas derecursos turísticos; Da: densidad de población (habitantes $/ \mathrm{km}^{2}$ ); H: norma de plazas de alojamiento por habitante según la infraestructura creada.

La red de instalaciones turísticas está desigualmente distribuida, esto se explica no sólo por la dispersión de los recursos naturales e históricos-culturales, sino también, por la desigual distribución territorial de la población. Por regla general, dichas empresas se localizan en las zonas más valiosas desde el punto de vista de los recursos y en áreas aledañas a los focos de fuerte desarrollo socio-económico. En todos los casos, un papel determinante lo ha desempeñado siempre la situación geográfico-económica de las áreas turísticas respecto a las zonas densamente pobladas. A partir de la propuesta de regionalización, se elaboró una tipología de las regiones turísticas sobre la base de cuatro indicadores: nivel de desarrollo de la infraestructura según su categoría; porcentaje de vacacionistas atendiendo al nivel de asimilación turística del territorio; posibilidades de cambios cualitativos en su desarrollo, y carácter predominante de la distribución de las instalaciones turísticas.

\section{Ordenamiento territorial del turismo en Cuba}

La planificación territorial del turismo en Cuba en sus diferentes niveles se ha realizado de manera centralizada por el $\mathrm{IPF}^{*}$ y el antiguo INTUR, en interrelación con otros organismos que comercializan 
y operan el turismo, tales como: la Corporación Cubanacán, S. A., y el Grupo de Turismo Gaviota, y otras instituciones relacionadas con el uso y conservación del patrimonio natural y cultural. El mecanismo empleado para el proceso de planificación se fundamentó en la realización del Esquema de Desarrollo del Turismo Nacional hasta el año 2000. Este documento sirve como instrumento de trabajo para la elaboración de los planes y programas de desarrollo del turismo nacional en todas las provincias. Sus objetivos generales fueron: definir la política a seguir para el desarrollo futuro del turismo; estimar los incrementos en la infraestructura para satisfacer las demandas de la población, y proponer la distribución territorial de la base material que satisfaga las necesidades de descanso y turismo. El potencial del territorio se calculó a partir de la evaluación de los recursos naturales y antrópicos con que se cuentan. Para ello se clasificaron los recursos en tres tipos: playas, otros recursos naturales (ríos, presas, lagunas, macizos montañosos, etc.) y ciudades.

Desde el punto de vista de la calidad, los recursos existentes no son homogéneos, por esta razón, se clasificaron también en tres categorías: mixtos, cuando poseen cualidades excepcionales que permiten utilizarlos para el turismo internacional y nacional; provinciales, cuando ostentan buenas condiciones para el turismo, en lo fundamental nacional; locales, cuando su calidad es relativamente baja, pero pueden servir a visitantes que residen dentro de un radio de acción relativamente reducido.

La capacidad del potencial de cada recurso se evaluó de acuerdo con distintas normas cubanas y la Instrucción Metodológica para la Proyección del Ordenamiento del Descanso y el Turismo. De esta forma, para la tipología de playas se utilizó el criterio de aquellos que se localizan cercanas a núcleos poblacionales de cualquier categoría, se evaluaron con una norma de cinco $\mathrm{m}^{2}$ /bañista, mientras que las alejadas de núcleos poblacionales, de categoría provincial o local, se evaluarían con una norma de $10 \mathrm{~m}^{2} /$ bañista y para los mixtos, $20 \mathrm{~m}^{2} / \mathrm{ba}$ ñistas.

Estimar el potencial de uso turístico de las montañas, ríos, lagunas, presas y otros recursos, requiere de un estudio previo de años, el cual permita evaluar el comportamiento de las cargas de usuarios 
sobre los recursos. Sobre este aspecto, existe poca experiencia en Cuba, por lo cual, las normas se han estimado principalmente en función de la demanda con un margen de seguridad amplio. En el caso de los ríos se utiliza una norma de dos bañistas por metro lineal de la orilla del río con posibilidad de baño y 2,5 bañistas por metro lineal de borde para las presas y lagunas con posibilidad de baño.

En lo relativo a las ciudades, se determinó que aquellas que poseen el potencial requerido para atender el turismo internacional son: La Habana, capital de la República, las demás cabeceras provinciales y las ciudades de Manzanillo, Trinidad, Baracoa y Nueva Gerona. El análisis de la base material para ejecutar el Esquema de Desarrollo del Turismo Nacional hasta el año 2000, partió de una subdivisión en dos tipologías: alojamiento y visitantes por un día. Las normas para el cálculo de las áreas requeridas fueron: para el alojamiento de 12 $\mathrm{m}^{2}$ /plaza y $16 \mathrm{~m}^{2} /$ plaza de área construida en instalaciones de una y dos estrellas, así como de tres, cuatro y cinco estrellas respectivamente: para el equipamiento de igual forma, $10 \mathrm{~m}^{2} /$ plaza y $12 \mathrm{~m}^{2}$ / plaza, y para áreas libres, $35 \mathrm{~m}^{2} /$ plaza y $45 \mathrm{~m}^{2} /$ plaza.

Para los visitantes por un día deben existir un grupo de facilidades, que según sus normas son: Gastronomía, $0,15 \mathrm{~m}^{2} /$ visitantes; instalaciones sanitarias, $0,16 \mathrm{~m}^{2} /$ visitantes; de parqueo, 1,5 $\mathrm{m}^{2} /$ visitantes; deportistas y recreativas, $3 \mathrm{~m}^{2} /$ visitantes; áreas verdes, $14 \mathrm{~m}^{2} /$ visitantes.

Como premisa general para el desarrollo, se tomó en consideración que se debía aprovechar al máximo las potencialidades de los recursos, en especial aquellos que se encontraban en explotación. Otro aspecto se refirió al hecho de que era necesario lograr el mayor nivel de satisfacción de la demanda con el menor gasto en inversiones y cuando se requería realizar inversiones hacerlas de fácil ejecución con presupuestos locales. De acuerdo con los anteriores criterios, se determinó priorizar las instalaciones que brindarán facilidades para visitantes por un día, y tratar de vincularlas con aquellos recursos de más fácil acceso. Asimismo se estimó necesario priorizar el desarrollo de la modalidad del campismo, por lo económico que resulta esta variante a la población.

En forma específica se consideraron también otros elementos, como son: la necesidad de garantizar la demanda dentro de los lími- 
tes de las provincias, en rangos lógicos de accesibilidad; y el tratar de satisfacer la mayor demanda de la población nacional como tendencia general.

En todo trabajo de planificación es importante disponer de una amplia base informativa, que revele el comportamiento del fenómeno estudiado. Al no disponer de toda la información necesaria, se partió para la planificación del turismo de una serie de hipótesis que sustentaban la proyección de la demanda. De esta forma se consideró que: a) Al final del período planificado se tendrá una población de 11.800.000 habitantes, de los cuales 8.500.000 serán urbanos. b) El $80 \%$ de la población urbana y el $65 \%$ de la rural disfrutarán de descanso anual. De ellos demandarán alojamiento, en el primer caso, el $40 \%$ y, en el segundo, el $35 \%$, mientras el resto demandará la modalidad de visitantes por un día. c) En relación con la estacionalidad, el $50 \%$ de la población vacacionará en los meses de julio y agosto. d) Existirá una rotación de cinco días, un aprovechamiento del alojamiento del $90 \%$ en los meses de verano y un $80 \%$ de ocupación en los restantes.

Por esta vía se llegó a la conclusión de que serían necesarias 165.000 plazas de alojamiento para satisfacer la demanda del turismo nacional en julio y agosto y alrededor de unas 46.000 para el resto del año. En cuanto a los visitantes por un día, se deberán alcanzar 1.400.000 instantáneos en el período de mayor demanda y cerca de 350.000 en los meses restantes. Respecto al descanso de fin de semana, se estimó que el $15 \%$ de la población urbana y el $5 \%$ de la rural demandaría esta modalidad, de los que solicitarán alojamiento, el $10 \%$ y el $5 \%$ respectivamente.

En esta proyección se consideró también que para la población urbana el comportamiento por tipos de recursos, se reflejaría del modo siguiente en cuanto al alojamiento: $50 \%$ playas, $30 \%$ otros recursos naturales y $20 \%$ ciudades. este mismo comportamiento para la población rural se estimó en un 50, 20 y $30 \%$. En lo relativo a los visitantes por un día, el indicador de la población urbana y rural se calculó igual, de forma tal que un $50 \%$ visite las playas, un $30 \%$ otros recursos naturales y sólo un $20 \%$ las ciudades. Por último, se llegaron a determinar los incrementos necesarios en la infraestructura por medio de un 
balance, que incluyó la situación de partida en relación con la base material y los cálculos que arrojaron la aplicación de diferentes hipótesis, teniendo en cuenta los potenciales de cada territorio.

El modelo de planificación propuesto se adecua a los distintos requerimientos analizados y a las tendencias más modernas en el campo de la planificación del turismo, este modelo puede aplicarse en Cuba y consta de tres fases de trabajo: análisis preliminar, síntesis de la estrategia y plan de desarrollo y control. Estas tres fases y sus etapas primarias y secundarias, conforman el esquema de planificación que puede ejecutarse a distintos niveles (nacional, provincial y local), según sus esferas de actuación (a corto, mediano y largo plazo).

\section{El turismo y la protección de la naturaleza en Cuba}

La modificación de la naturaleza de Cuba estuvo caracterizada por una débil y localizada acción de los aborígenes y una intensa e irracional explotación de los recursos, apoyada por intereses y capitales foráneos, primero españoles y después norteamericanos. Cuatrocientos años de administración colonial española fueron suficientes para dañar seriamente la vegetación natural.

La promulgación por la Asamblea Nacional del Poder Popular en 1981 de la Ley número 33 de Protección del Medio Ambiente y el Uso Racional de los Recursos Naturales, establece los principios básicos para la protección, mejoramiento y transformación de la naturaleza. Una de sus secciones trata específicamente del paisaje y los recursos turísticos, y dispone, no obstante su carácter general, determinadas regulaciones para las zonas de uso turístico. Esta Ley crea, además, el Sistema Nacional de Protección del Medio Ambiente, conformado por varios subsistemas, uno de ellos es el subsistema de los recursos turísticos y el paisaje, a cargo del INTUR como organismo rector.

Con posterioridad, se legisló al Decreto-ley número 118 de 1990 sobre Estructura, Organización y Funcionamiento del Sistema Nacional de Protección del Medio Ambiente y del Uso Racional de los Recursos Naturales y sus Órganos Rectores, que tiene como objeto brindar una atención nacional al medioambiente y a los recursos naturales. 
Se han aprobado también tres normas estatales dirigidas a lograr una mejor organización y conservación de las zonas turísticas. En ordenamiento territorial de las playas; las medidas generales para la protección, limpieza y mantenimiento de las mismas y en la tercera, los requisitos de proyectos para las áreas verdes en zonas turísticas.

Para realizar un análisis objetivo del uso y protección de los recursos turísticos, es necesario establecer dos etapas muy diferentes de este desarrollo en Cuba: la primera, desde 1902-1958, y la segunda, a partir de 1959. En la primera etapa, la explotación turística de los recursos estaba caracterizada por: a) La existencia de la propiedad privada de los principales recursos turísticos, los cuales pertenecían a individuos o empresas, principalmente extranjeros y en lo fundamental norteamericanos. b) El acceso al uso de los recursos turísticos, incluyendo las playas, estaba muy restringido a la población local. c) La planificación de la explotación de los recursos se realizaba a corto plazo con el propósito de obtener grandes ganancias en poco tiempo, sin interesarse por el deterioro que esa explotación le ocasionaba al paisaje, resultado de proyectos aislados y de normas inadecuadas de manejo de los recursos.

Las legislaciones existentes eran violadas en la práctica, los sitios que se explotaban para el turismo se transformaba de modo irracional, degradando en breve plazo los valores naturales e histórico-culturales que poseían. Sólo se conservaban en su estado relativamente natural, aquellos paisajes que no se utilizaban, ni para el turismo ni con otros fines económicos.

En la segunda etapa se pone a disposición de la población los grandes y diversos recursos turísticos que posee Cuba. Esa política se manifiesta desde las primeras leyes y decretos promulgados, y se refleja en la Constitución de la República de Cuba, en su artículo 43 «El Estado consagra el derecho conquistado por la Revolución, de que los ciudadanos sin distinción de raza, color u origen nacional, puedan (...) disfrutar de los mismos balnearios, playas, parques, círculos sociales y demás centros de cultura, deportes, recreación y descanso».

Consecuente con esta política, los planes de desarrollo del campismo popular constituyen una expresión de la intención, por parte del Estado, de buscar solución a las crecientes demandas turísticas 
de la población nacional, y de lograr optimizar, al mismo tiempo, las relaciones que se establecen entre los turistas y la naturaleza. Es bueno reiterar que el turismo no es incompatible con la protección de los recursos, aunque en ocasiones ambos propósitos sean difíciles de compatibilizar y parezcan hasta contrapuestos. Un adecuado plan de manejo ambiental permite relacionarlos de manera conveniente.

\section{El Ecoturismo en Cuba}

Uno de los retos que enfrentan Cuba es diversificar su producto turístico, teniendo en cuenta que históricamente se ha conformado de sol y playa, por lo que es imprescindible reorientar los flujos turísticos hacia los valores de la naturaleza cubana. Cuba cuenta para desarrollar el Ecoturismo con amplios potenciales naturales e histórico-culturales, gran riqueza y endemismo de la flora y fauna en áreas pequeñas, clima tropical, insularidad múltiple y estructura geolo-geomorfológica de particular interés (un porcentaje elevado de rocas carbonatadas en las que se desarrollan procesos cársicos) esto provoca la presencia de bellos y singulares paisajes naturales.

En Cuba la situación ecólogo-ambiental no tiene el estado de crisis inherente a algunos países de Latinoamérica, y encontraremos en gran parte del territorio un desarrollo equilibrado y sostenido de los sistemas ecológicos, aunque sí existen algunos problemas puntuales (contaminación de las bahías, pérdida de valores naturales en algunas regiones; suelos degradados, etc.) (Mateo, J. 1992).

En las decisiones para desarrollar el Ecoturismo se debe priorizar la protección de los recursos estético-escénico de los paisajes, la conservación de aquellos elementos que garantizan el balance ecológico, en particular los recursos ecológicos, florísticos y faunísticos y el genofondo, así como el establecimiento de un sistema de áreas protegidas que asegure la explotación racional de los recursos (Mateo, 1992).

En la propuesta de Estrategia de Desarrollo del Ecoturismo en Cuba (Grupo Nacional de Ecoturismo, marzo 1994) se plantean los siguientes aspectos: 
- El desarrollo del turismo en áreas naturales y en especial el Ecoturismo deben contribuir a la conservación del patrimonio natural e histórico-cultural y al desarrollo socio-económico sostenible.

- Definición del potencial Ecoturístico Nacional y selección de las áreas para la práctica del Ecoturismo, en armonía con otras actividades socio-económicas. Declaración de valores naturales e histórico-culturales. Implementación de planes y categorías de manejo.

- Establecimiento de las normas generales de conducta de visitantes, inversionistas, turoperadores y otro tipo de especialistas vinculados a la actividad.

- Desarrollar la imagen y estrategia de promoción para la fase de iniciación de la modalidad.

- Introducción de Cuba en el mercado Ecoturístico del Caribe definiendo un producto ecoturístico cubano.

- Definir conceptos básicos como son: tipos de ofertas, capacidades de carga, infraestructura local mínima y común para el desarrollo de la actividad a escala nacional.

- Preparación del personal técnico de apoyo que enfrentará el desarrollo de la actividad con énfasis en la especialización sistemática de los guías.

- Impulsar la educación ambiental y su papel en el desarrollo del Ecoturismo.

En la propuesta de desarrollo inicial del Ecoturismo en Cuba, las áreas que se han definido para la primera etapa de implementación de esta modalidad son: Reserva de la Biosfera «Sierra del Rosario»; Área Protegida «Mil Cumbres»; Monumento Nacional «Valle de Viñales»; Área Protegida «La Guabina»; Parque Nacional «Ciénaga de Zapata»; Parque Natural «Tope de Collantes»; Patrimonio de la Humanidad Centro Histórico de «Trinidad y Valle de los Ingenios»; Área Protegida «Cayo Saetía»; Área Protegida «Bahía de Naranjos»; Área Protegida «Parque de Mayari»; Gran Parque Nacional «Sierra Maestra».

Estas áreas presentan altos valores naturales, una infraestructura de alojamiento adecuada y una política establecida de protección y 
manejo. Es importante el establecimiento de criterios coherentes para la promoción de Cuba como destino ecoturítico y en esta dirección esencial la definición de la imagen tanto en su forma como en su contenido, es un aspecto fundamental.

\section{Principales direcciones en los estudios de Ecoturismo}

El Grupo de Geología y Turismo de la Facultad de Geografía de la Universidad de La Habana, ha realizado diversos estudios para el desarrollo de un turismo donde la naturaleza ocupa la posición central. La concepción científica utilizada ha sido desarrollada por este grupo de trabajo sobre la base del análisis y evaluación del paisaje como un sistema que abarca los componentes naturales, antroponaturales, socio-culturales y el paisaje visual. Los estudios se han centrado hasta el momento en el diagnóstico y evaluación de los recursos naturales, histórico-culturales y socio-económico para la propuesta de ordenamiento geoecológico en diversos territorios del país a diferentes escalas, los que trataremos de resumir a continuación:

a) Estudios a escalas pequeñas donde se inventarían y caracterizan los recursos turísticos de diversas regiones y de todo el país como son: Estudio del Turismo de Montaña en Cuba, el Turismo Rural en el Occidente y los Recursos Turísticos de la Sierra de Trinidad, entre otros, en general en estos estudios se realiza el análisis de los potenciales de recursos para el desarrollo del turismo en estas regiones, las opcionales del turismo de la naturaleza que están ofertando las diferentes entidades turísticas para evaluar la compatibilidad de estas opcionales con los potenciales y finalmente realizar propuestas para el reordenamiento de la actividad ecoturística en estos territorios relacionando la utilización de los recursos con la protección del Patrimonio natural e histórico-cultural.

b) Estudios a escalas medias donde sobre la base del inventario y diagnóstico de los paisajes se determinan y evalúan los recursos turísticos clasificados en: naturales, históricos-culturales, socio-económicos y estético-escénicos. Se han realizado especialmente en áreas bajo diferentes regímenes de protección, pero incluidas en el Sistema

$$
-346-
$$


de Áreas Protegidas de nuestro país, como son: Reservas de la Biosfera Sierra del Rosario y Península de Guanahacabibes, Parque Nacional Desembarco del Granma, Sierra de Nipe y Llanura Sur de la Isla de la Juventud. En general, en estos estudios a escalas medias se confeccionan una serie de matrices para facilitar la evaluación, especialmente lo estético-escénico, al final se realiza una propuesta de manejo de cada área sobre la base de la zonificación funcional integrando las actividades ecoturísticas a la protección de la naturaleza con vistas a lograr un desarrollo sustentable en estos territorios.

c) Otra dirección importante en los estudios a escalas medias son los realizados en diferentes municipios y provincias del país como es el caso de la provincia de Sancti Spíritus, en la región central de Cuba, en este caso, sobre la base de un mapa de paisaje, se aplicó una matriz para evaluar los potenciales naturales e históricoculturales para el desarrollo de actividades ecoturísticas, se evaluaron los elementos naturales e histórico-culturales de interés, una serie de indicadores generales de los paisajes como son: naturalidad, diversidad, atracción, singularidad, etc., así como aquellos factores que pueden convertirse en limitantes para el desarrollo del Ecoturismo (accesibilidad, transitabilidad y presencia de vectores entre otros). Finalmente se proponen las funciones principales que deben cumplir los paisajes y las actividades posibles a desarrollar en cada unidad.

d) Por último, se han realizado estudios a escalas detalladas de otras áreas con el fin de la caracterización y cartografía de los paisajes como base para la evaluación de las posibilidades de desarrollar actividades ecoturísticas y finalmente proponer los senderos, etc. Se han utilizado técnicas novedosas de procesamiento digital. Como caso representativo tenemos los estudios realizados en: «Loma del Puerto» y Cayo Coco; en la microreserva Rincón de Guanabo y en el Nicho en la Sierra de Trinidad, este último sirvió como base para la comercialización por la Empresa Rumbos, S. A., de una opcional ecoturística de gran aceptación por parte de los turistas. En estos estudios a escalas detalladas además de la evaluación de los potenciales naturales e histórico-culturales para el desarrollo del Ecoturismo, se analiza el impacto que puede causar dicha actividad y se realizan cálculos de la capacidad de carga, lo que permitirá la explotación de los 
recursos sin que los valores de estas áreas sean afectados, logrando la sustentabilidad de estas actividades en los territorios.

\section{Consideraciones finales}

El turismo nacional e internacional han tenido un crecimiento sostenido en cuanto al número de visitantes y la cantidad de los ingresos en los últimos años y perspectivamente, esta tendencia de incremento debe mantenerse. El crecimiento que ha tenido el turismo nacional puede explicarse entre otras causas, por el aumento del nivel adquisitivo y cultural de la población cubana y la mayor facilidad para disponer de su tiempo libre.

En cuanto al turismo internacional en 1992 se recibieron 460.510 turistas y en 1993, la cifra alcanzó los 546.000 visitantes. A su vez cerca de 620.000 turistas provenientes en su mayor parte de Canadá, España y Alemania pasaron sus vacaciones en Cuba, en 1994, lo que representó un $11,8 \%$ de incremento con respecto al año 1993. Por otra parte, las capacidades hoteleras se han incrementado con un alto ritmo de crecimiento en las construcciones, en 1992 existían 18.662 , en 1993 se contaba con 22.561 habitaciones internacional y en 1994 la cifra alcanzaba las 23.254 habitaciones.

Cuba ha tenido en los últimos cinco años crecimientos significativos por encima del $17 \%$ (unos 800 millones de dólares en ingresos brutos en 1994) y se espera alcanzar el año 2000 con cifras que superen los dos millones de vacacionistas.

En lo referente a los recursos turísticos, tanto naturales como antrópicos, Cuba se destaca por poseer abundantes y variados: el clima, la estructura geólogo-geomorfológica y su carácter insular son los factores físico-geográficos más importantes que determinan el potencial turístico-recreativo de sus recursos naturales, especialmente de sus paisajes, además de valiosos recursos históricos-culturales, conjugados con la hospitalidad y seguridad que brinda el pueblo cubano.

En las condiciones tropicales de Cuba se demostró que la función turística de los territorios está estrechamente relacionada con las características particulares de sus paisajes. Las zonas de mayor interés 
turístico y desarrollo perspectivo están ubicadas en su gran mayoría en las costas.

El desarrollo turístico se concentrará en ocho regímenes a saber: La Habana, Varadero, Costa Norte de Ciego de Ávila (Cayo Guillermo y Cayo Coco), Costa Norte de Camagüey (Cayo Sabinas, Cayo Cruz y otros), Zona Norte de Holguín, Trinidad-Cienfuegos, Cayo Largo-Isla de la Juventud y finalmente la costa sur de la Sierra Maestra (véase figura 1).

El desarrollo del Ecoturismo en Cuba ha estado asociado con los parques nacionales, parques naturales y áreas protegidas, lugares con elevada naturalidad, valiosas especies de flora y fauna, etc.

\section{BIBLIOGRAFÍA}

Avella, A. (1985): Principales direcciones de las investigaciones económico-geográficas de planificación de la rama recreativa en Cuba. Tesis de doctorado, Universidad Est. de Moscú (en ruso).

-, y Salinas, Er. (1991): «La planificación como forma de ordenamiento de la actividad turística», Revista Temáticas Turísticas, núm. 1, pp. 19-28. Centro de Investigaciones y Documentación para América Latina y el Caribe. La Habana, Cuba.

Benavides, R.; Fernández, B., y Martínez, A. (1982): Estudios de la distribución territorial de los turistas en Cuba. La Habana, Cuba.

Comité estatal de estadisticas (1986): Anuario Estadistico de Cuba. La Habana, Cuba.

CAmpos, R. (1995): «La hotelería cubana incrementa sus posibilidades», pp. 20-21, Revista Destinos. La Habana, Cuba.

Estévez, R.; Salinas, Ed., y GutiÉRREZ, O. (1995): «Principales direcciones de los estudios sobre Ecoturismo en la Facultad de Geografía de la UH». Ponencia presentada en el VEncuentro de geógrafos de América Latina. La Habana.

GonzÁlez, G. (1980): «El desarrollo del turismo en Cuba», Revista Cubaturismo, núm. 1, año 4, La Habana, Cuba.

INSTITUTO DE PLANIFICACIÓN FISICA NACIONAL (1982): Instrucción metodológica para el ordenamiento y la proyección del descanso y el turismo. La Habana, Cuba.

InSTITUTO NACIONAL DE TURISMo (1978): Inventario de los recursos turisticos. Guía Metodológica. La Habana, Cuba.

- (1979): Regionalización turistica de Cuba. La Habana, Cuba, pp.

- (1984): Pronóstico del desarrollo turístico de Cuba. Informe al XI Congreso del CLAPTUR. La Habana, Cuba.

- e Instituto de PLANIFICACIÓN Fisica (1985): Esquema de Desarrollo del Turismo Nacional hasta el año 2000 (segunda versión). La Habana, Cuba.

LEY NÚMERO 33 DE PROTECCI;ON DEL MEDIO AMBIENTE Y DEL USO RACIONAL DE LOS RECURSOS NATURALES (1981): Gaceta Oficial, año LXXIX, núm. 17. La Habana, Cuba. 
Lineamientos económicos y sociales para el quinquenio 1981-1985. Editora Política. La Habana, Cuba.

MAteo, J. (1992): «Ecología y socialismo: reflexiones sobre la experiencia cubana en investigaciones sobre Medio Ambiente», pp. 3-5. Flacso-Cuba y SodePaz, La Habana.

Pevida, A. (1988): Pronóstico geográfico de la utilización de los recursos recreativos en Cuba. Tesis de doctorado. Universidad Estatal de Moscú (en ruso).

Salazar, A. (1992). «XIII Convención de Turismo», Revista Bohemia, año 84, núm. 23. La Habana, Cuba.

SAlinas, Er. (1986): Fundamentos geográfico-paisajisticos de la organización del turismo en Cuba. Tesis de Doctorado, Universidad Estatal de Ucrania, 142 pp. (en ruso).

-, y GuTIÉRREz, I. (1990): «El turismo de montaña en Cuba», Revista Flora y Fauna y Áreas Silvestres, año 4, núm. 12. Oficina Regional de N. FAO, Chile.

- (1994): «Turismo, Medio Ambiente y Desarrollo» en Imagen y Turismo, año 3, núm. 4, pp. 18-19. Universidad Nacional de COMAHUE. Neuquén, Argentina.

-, y Avella, A. (1992): «Tendencias actuales en el desarrollo de los trabajo prácticos e investigaciones sobre turismo en Cuba», Revista Estudios y Perspectivas en Turismo, vol. 1, núm. 4, pp. 291-300. Centro de Investigaciones y Estudios Turísticos, Buenos Aires, Argentina.

-, Avella, A., y BeNA VIDES, R. (1994): Turismo, naturaleza y sociedad, Ed. Ciencias Sociales. La Habana (en prensa).

SANTANa, O. (1980): Estudio sobre el empleo del tiempo en la población urbana de Cuba, ICIODI, La Habana, Cuba.

Shluter, R. G. (1983): Turismo y Parques Nacionales, Centro de Estudios e Investigaciones Turísticas, Buenos Aires.

Villalba, E. (1979): El turismo en Cuba, Instituto Nacional de Turismo, La Habana, Cuba.

- (1993): Cuba y el turismo, 205 pp. Ed. de Ciencias Sociales. La Habana, Cuba.

Resumen: El turismo es una de las actividades más importantes en los planes de desarrollo socioeconómico cubano. En la estrategia del desarrollo del turismo se le ha dado prioridad al turismo internacional, como medio de captación de divisas, tan necesarias a la economía y para mejorar el nivel de vida de la población. También el desarrollo de un turismo integrado a la naturaleza (Ecoturismo) como forma de diversificar su producto turístico y utilizar los grandes potenciales naturales e histórico-culturales del país. El presente artículo aborda de forma amplia los principales aspectos de la actividad turística en Cuba. Así como el origen y evolución del turismo en la isla, los problemas territoriales del sector, la relación entre el desarrollo del turismo y la protección de la naturaleza y las perspectivas de un nuevo tipo de turismo para el país: el Ecoturismo.

Palabras claves: Turismo. Regiones turísticas. Ecoturismo. Ordenamiento del Territorio. Protección de la naturaleza. 